\title{
Pilot study of ziv-aflibercept in myopic choroidal neovascularisation patients
}

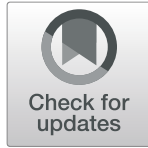

\author{
Amin E. Nawar ${ }^{*}$ and Heba M. Shafik
}

\begin{abstract}
Background: Myopic choroidal neovascularization (CNV) is the most common sight-threatening complication associated with high myopia. The present study evaluated the efficacy and safety of the intravitreal injection of zivaflibercept in patients with myopic CNV.

Methods: This prospective interventional study was conducted on 20 eyes of 20 patients with active myopic CNV. Twelve patients were 40 years or older. This study was performed in the Ophthalmology Department of Tanta University Eye Hospital, Tanta University, Egypt. Optical coherence tomography (OCT) was performed for all patients at baseline and monthly after injection during the 6-month follow up period. The main outcome measures were changes in BCVA and CMT. The exploratory outcome measures were CNV size, IOP and the number of injections needed in each age group during the study period.
\end{abstract}

Results: Patients with myopic CNV younger than 40 years needed fewer injections $(2.00 \pm 0.76)$ than patients older than 40 years $(2.50 \pm 1.00)$, with no statistical significance detected between the two groups ( $p$-value 0.246). CNV was smaller in the younger age group ( $p$-value 0.209), best corrected visual acuity (BCVA) improved significantly in the younger and older age groups ( $p$-values 0.001 and 0.028 , respectively), and central macular thickness (CMT) decreased significantly after 6 months, from $242.88 \pm 23.83 \mu \mathrm{m}$ to $191.13 \pm 13.83 \mu \mathrm{m}$ in the younger age group and from $251.33 \pm 26.60 \mu \mathrm{m}$ to $197.08 \pm 17.64 \mu \mathrm{m}$ in the older age group $(p=0.001)$. No significant correlation was found between the final BCVA and either the spherical equivalent or central macular thickness after 6 months, with $p$-values of 0.135 and 0.145 , respectively. No significant changes in IOP were detected in either group after the intravitreal injection.

Conclusion: Ziv-aflibercept is a highly effective and safe drug in cases of active myopic CNV; however, a larger number of patients and a longer follow-up period are needed to confirm our results.

This study was retrospectively registered at clinicaltrials.gov (ID: NCT04290195) on 26-2-2020.

Keywords: Central macular thickness, Choroidal neovascularization, Optical coherence tomography, Pathological myopia, Ziv-aflibercept

\footnotetext{
* Correspondence: nawar20012002@gmail.com

Department of Ophthalmology, Tanta University, Tanta, Egypt
}

(c) The Author(s). 2020 Open Access This article is licensed under a Creative Commons Attribution 4.0 International License, which permits use, sharing, adaptation, distribution and reproduction in any medium or format, as long as you give appropriate credit to the original author(s) and the source, provide a link to the Creative Commons licence, and indicate if changes were made. The images or other third party material in this article are included in the article's Creative Commons licence, unless indicated otherwise in a credit line to the material. If material is not included in the article's Creative Commons licence and your intended use is not permitted by statutory regulation or exceeds the permitted use, you will need to obtain permission directly from the copyright holder. To view a copy of this licence, visit http://creativecommons.org/licenses/by/4.0/ The Creative Commons Public Domain Dedication waiver (http://creativecommons.org/publicdomain/zero/1.0/) applies to the data made available in this article, unless otherwise stated in a credit line to the data. 


\section{Background}

The prevalence of pathological myopia in adults is approximately $1-3 \%$, and myopic choroidal neovascularisation (CNV) is one of the most sight-threatening complications, occurring in approximately $5-11 \%$ of pathological myopia patients [1,2]. Several treatment approaches have been proposed due to the poor understanding of its pathological nature [2]. Photodynamic therapy (PDT) is one of the treatment options for myopic CNV that can reduce the risk of visual loss, as supported by several studies [3, 4]. However, patients treated with PDT showed limited improvement in the mean visual acuity that did not remain longer than 2 years [5]. Recently, antivascular endothelial growth factor (anti-VEGF) agents such as bevacizumab, ranibizumab, and aflibercept were introduced for the treatment of many retinal diseases, with high safety profiles. The off-label use of bevacizumab and the introduction of ranibizumab and aflibercept as treatment modalities for myopic $\mathrm{CNV}$ showed promising results in preventing visual deterioration for a long time with minimal side effects [6,7]. According to the phase 3 RADIANCE trial [8], ranibizumab has been approved for the treatment of visual impairment due to myopic CNV; in addition, MYRROR, a phase 3 study, confirmed the efficacy and safety of intravitreal aflibercept in the treatment of CNV in pathological myopia patients [9].

Ziv-aflibercept (Zaltrap; Regeneron, New York, USA) is a recombinant fusion protein that is very similar to aflibercept. It was approved by the FDA in August 2012 for the treatment of resistant metastatic colorectal carcinoma. Recently, it was reported that off-label intravitreal ziv-aflibercept is an effective and safe treatment at 4-week intervals, without any ocular toxicity in patients with age-related macular degeneration [10].

The present study evaluated the efficacy and safety of ziv-aflibercept as a primary treatment in patients with myopic $\mathrm{CNV}$ younger than and older than 40 years.

\section{Methods}

Study design

This prospective interventional case study was conducted on 20 eyes of 20 patients with active myopic CNV who attended the outpatient clinic of Tanta University Eye Hospital between March 2019 and September 2019 after approval from the Ethical Committee of the Faculty of Medicine, Tanta University, Egypt (approval code 32970/02/19). Patients were divided into two age groups to detect the influence of age on visual prognosis: group 1 included 12 patients $\geq 40$ years old, and group 2 included the remaining eight patients, who were $<40$ years old. Sample size calculation was based on the mean (SD) of BCVA pre- and post-treatment with ziv-aflibercept $(0.67(0.45)$ and $0.58(0.43)$, respectively, based on previous research) [11]. G* power version
3.0.10 was used to calculate the difference between 2 paired readings using a 2-tailed $t$ test with an $\alpha$ error $=$ 0.05 , a power $=80.0 \%$ and an effect size $=0.65$. The total calculated sample size was 20 cases.

All procedures were carried out under the tenets of the Helsinki Declaration. Written consent was provided by all participants after discussing the procedure, alternative treatment plans, follow-up schedules, and possible benefits and risks. This study was retrospectively registered at clinicaltrials.gov (ID: NCT04290195) on 26-22020.

\section{Participants}

This study included treatment-naive patients who were recently diagnosed with active myopic subfoveal or juxtafoveal CNV for less than 2 months that was confirmed by fundus fluorescein angiography (FFA) and optical coherence tomography (OCT). Fifteen cases of subfoveal $\mathrm{CNV}$ and five cases of juxtafoveal $\mathrm{CNV}$ were included. Pathological myopia patients with a spherical equivalent $\geq-6$ diopters and an axial length of $\geq 26 \mathrm{~mm}$ were enrolled in the current study.

Patients with a history of intraocular surgery, coincident retinal pathology such as diabetic retinopathy, retinal vein occlusion (RVO), CNV due to other causes such as age-related macular degeneration, angioid streaks, trauma, choroiditis and extrafoveal myopic CNV were excluded from the study. In addition, patients who received other lines of treatment for $\mathrm{CNV}$, such as photodynamic therapy, laser photocoagulation or intravitreal injection of triamcinolone or other anti-VEGF agents, and those known to be glaucomatous or have an IOP $\geq 20 \mathrm{mmHg}$ were also excluded.

Furthermore, patients with other retinal pathologies, such as prior ocular inflammation, retinal degeneration, and dense media opacity, including nuclear sclerosis, and those who did not complete 6 months of follow-up were not enrolled in the present study.

A thorough ophthalmic evaluation, including a BCVA test using a Snellen chart that was converted to LogMAR for statistical analysis, IOP measurements using applanation tonometry, an anterior segment examination using a slit lamp, a posterior segment examination by slit lamp bimicroscopy using a $+78 \mathrm{D}$ lens, and indirect ophthalmoscopy, was performed for all patients. Spectral-domain OCT (Topcon 3D Optical Coherence Tomography) was performed for all patients at baseline and at the postoperative first-month visit and then monthly for 6 months.

\section{Surgical procedure}

\section{Preoperative preparation}

Patients were prepared by applying topical fluoroquinolone eye drops (moxifloxacin hydrochloride 0.5\% 
Vigamox, Alcon, USA) 4 times daily for 3 days before injection.

\section{Procedure}

The intravitreal injection was carried out in the operating room under complete aseptic techniques with an operating microscope. After the topical application of anaesthetic drops (benoxinate hydrochloride 0.4\%, Benox, Epico, Egypt) to the ocular surface followed by the topical application of $10 \%$ povidone-iodine (Betadine) to the periocular area, lids and eye lashes, $5 \%$ povidone iodine was administered inside the conjunctival sac for $3 \mathrm{~min}$ before the intravitreal injection. Next, $0.05 \mathrm{ml}$ of $1.25 \mathrm{mg}$ of ziv-aflibercept (Zaltrap) was injected into the vitreous cavity in the inferotemporal quadrant of the globe using a 30-gauge needle $4 \mathrm{~mm}$ from the limbus.

\section{Postoperative care}

After injection, topical antibiotic drops (moxifloxacin hydrochloride $0.5 \%$ Vigamox, Alcon, USA) were applied, and the eye was patched for several hours. Patients were instructed to administer antibiotic drops four times daily for 3 days. Patients were examined the following day and the third day after injection to exclude any complications, such as an elevated IOP, endophthalmitis, retinal breaks, retinal detachment and vitreous haemorrhage. All patients were followed up at 4-week intervals after the first injection. At each visit, a thorough ophthalmic examination and SD-OCT were performed. The pro re nata (PRN) regimen was followed in this study, in which an additional intravitreal injection of Zaltrap was given after 1 month and monthly for sixth months if there was no improvement in or stabilization of best corrected visual acuity (improvement by more than one line in the Snellen chart), haemorrhage was detected during the clinical examination, and/or persistent intraretinal or subretinal fluid was detected on SD-OCT.

Statistical analysis was conducted using Student's t-test, the chi-square test, the linear correlation coefficient, and analysis of variance (ANOVA) with the Statistical Package for Social Science (SPSS, Chicago, IL, USA). An unpaired Student's t-test was used to compare quantitative data between two groups. Data are presented as the mean and standard deviation. The chi-square value indicates that the row and column variables are independent but does not indicate the strength or direction of the relationship.

The Pearson correlation coefficient was used to detect correlations between two quantitative variables in one group. Student's t test and a paired t test were used to compare 2 continuous parametric variables ( 2 independent groups and 2 dependent groups, respectively). A $P$ value $\leq 0.05$ was considered significant.

\section{Results}

This study was performed from March 2019 until September 2019. Twenty eyes with active myopic CNV were collected beginning in March 2019, and the baseline demographic data of all patients, including age, sex, spherical equivalent, number of injections and CNV size, were recorded (Table 1 ).

Table 1 Demographic data, spherical equivalent, number of injections and the size of CNV

\begin{tabular}{|c|c|c|c|c|}
\hline & \multirow{2}{*}{$\begin{array}{l}\text { Total } \\
\text { number of } \\
\text { examined } \\
\text { eyes } \\
n=20\end{array}$} & \multicolumn{2}{|c|}{ Age of the studied cases } & \multirow{2}{*}{$\begin{array}{l}\text { Test of } \\
\text { significance }\end{array}$} \\
\hline & & $\begin{array}{l}<40 \text { years } \\
n=8\end{array}$ & $\begin{array}{l}\geq 40 \text { years } \\
n=12\end{array}$ & \\
\hline \multicolumn{5}{|l|}{ Age (years) } \\
\hline Range & $31-63$ & $31-39$ & $40-63$ & $P=0.001^{*}$ \\
\hline \multicolumn{5}{|l|}{ Gender n(\%) } \\
\hline Male & $8(40 \%)$ & $3(37.5 \%)$ & $5(41.7 \%)$ & $x^{2}=0.035$ \\
\hline Female & $12(60 \%)$ & $5(62.5 \%)$ & $7(58.3 \%)$ & $P=0.852$ \\
\hline \multicolumn{5}{|c|}{ Spherical equivalent } \\
\hline Mean \pm S. D & $-7.05 \pm 0.52$ & $-6.78 \pm 0.36$ & $-7.23 \pm 0.55$ & $t=2.03$ \\
\hline Range & $(-8)-(-6.25)$ & $(-7.25)-(-6.25)$ & $(-8)-(-6.25)$ & $P=0.058$ \\
\hline \multicolumn{5}{|l|}{ No of injections } \\
\hline Mean \pm S. D & $2.30 \pm 0.92$ & $2.00 \pm 0.76$ & $2.50 \pm 1.00$ & $t=1.198$ \\
\hline Range & $(1-4)$ & $(1-3)$ & $(1-4)$ & $p=0.246$ \\
\hline \multicolumn{5}{|c|}{ Size of CNV by disc diameter } \\
\hline Mean \pm S. D & $0.65 \pm 0.42$ & $0.59 \pm 0.37$ & $0.88 \pm 0.55$ & $\begin{array}{l}t=1.30 \\
p=0.209\end{array}$ \\
\hline
\end{tabular}

No Number, S.D Standard deviation, $\mathrm{x}^{2}$ Chi-Square test, $t$ Student $\mathrm{t}$ test 
Table 2 BCVA and CMT at the base line and after 6 months of follow up

\begin{tabular}{|c|c|c|c|c|}
\hline & \multirow{2}{*}{$\begin{array}{l}\text { Total } \\
\text { number of } \\
\text { examined } \\
\text { eyes } \\
n=20\end{array}$} & \multicolumn{2}{|c|}{ Age of the studied cases } & \multirow{2}{*}{$\begin{array}{l}\text { Test of } \\
\text { significance } \\
\text { (between } \\
\text { age groups) }\end{array}$} \\
\hline & & $\begin{array}{l}<40 \text { years } \\
n=8\end{array}$ & $\begin{array}{l}\geq 40 \text { years } \\
n=12\end{array}$ & \\
\hline \multicolumn{5}{|c|}{ BCVA Before injection } \\
\hline Mean \pm S. D & $0.77 \pm 0.28$ & $0.88 \pm 0.28$ & $0.60 \pm 0.21$ & $\mathrm{t} 1=2.56$ \\
\hline Range & $0.4-1.4$ & $0.4-1.4$ & $0.4-1$ & $p=0.0197$ \\
\hline \multicolumn{5}{|c|}{ BCVA After 6 months } \\
\hline Mean \pm S. D & $0.42 \pm 0.24$ & $0.48 \pm 0.23$ & $0.33 \pm 0.24$ & $\mathrm{t} 1=1.392$ \\
\hline Range & $0.1-1$ & $0.22-1$ & $0.1-0.7$ & $p=0.181$ \\
\hline t2 & 17.609 & 14.443 & 5.998 & \\
\hline$P$ value & $0.001^{*}$ & $0.001^{*}$ & $0.028^{*}$ & \\
\hline \multicolumn{5}{|c|}{ CMT (um) Before injection } \\
\hline Mean \pm S. D & $247.95 \pm 25.24$ & $242.88 \pm 23.83$ & $251.33 \pm 26.60$ & $\mathrm{t} 1=0.724$ \\
\hline Range & $212-289$ & $212-289$ & $213-287$ & $p=0.478$ \\
\hline \multicolumn{5}{|c|}{ CMT (um) After 6 months } \\
\hline Mean \pm S. D & $194.70 \pm 16.11$ & $191.13 \pm 13.83$ & $197.08 \pm 17.64$ & $\mathrm{t} 1=0.802$ \\
\hline Range & $165-235$ & $165-210$ & $175-235$ & $p=0.433$ \\
\hline t2 & 63.252 & 28.223 & 34.663 & \\
\hline$P$ value & $0.001^{*}$ & $0.001^{*}$ & $0.001^{*}$ & \\
\hline
\end{tabular}

BCVA Best corrected visual acuity, CMT Central macular thickness, No Number, S.D Standard deviation, $t 1$ Student $t$ test, $t 2$ Paired t test ${ }^{*} p$ value

\section{Primary and secondary outcomes}

Compared with baseline, BCVA improved significantly after 6 months of injection in both age groups, with a more notable improvement in the younger age group than the older age group, from a mean of $0.88(0.28)$ before injection to $0.48(0.23)(p=0.001)$ in patients $<40$ years old and from a mean of $0.60(0.21)$ before injection to 0.33 $(0.24)$ after 6 months $(p=0.028)$ in patients $\geq 40$ years old. The greatest improvement in BCVA was within the first 2 months. These results are shown in Table 2.

Also, patients with myopic CNV who were younger than 40 years needed significantly fewer injections $(2.00 \pm 0.76)$ than patients who were 40 years or older $(2.50 \pm 1.00)(p$ value 0.246 ). $\mathrm{CNV}$ was smaller in the younger age group, with a p-value of 0.209 . These results are shown in Table 1.

Furthermore, central macular thickness (CMT) decreased significantly after 6 months, from $242.88 \pm$ $23.83 \mu \mathrm{m}$ to $191.13 \pm 13.83 \mu \mathrm{m}$ in the younger age group and from $251.33 \pm 26.60 \mu \mathrm{m}$ to $197.08 \pm 17.64 \mu \mathrm{m}$ in the older age group at baseline $(p=0.001)$, as shown in Table 2.

Table 3 Illustrates changes in IOP after injection

\begin{tabular}{lllll}
\hline & & Before injection & After $\mathbf{6}$ months & Paired t test \\
\hline IOP & Mean \pm SD & $12.53 \pm 1.77$ & $13.47 \pm 1.60$ & $\mathrm{t}=1.517$ \\
& Range & $10-16$ & $10-16$ & $p=0.140$ \\
\hline
\end{tabular}

IOP Intra-ocular pressure
No significant change in IOP after the intravitreal injection was detected in either group after 6 months $(p=$ 0.140), as illustrated in Table 3.

Additionally, there was no significant correlation between the final BCVA and either the spherical equivalent or the final CMT after 6 months ( $p$-values 0.135 and 0.145 , respectively) (Table 4, Figs. 1 and 2).

Subconjunctival haemorrhage occurred in three eyes during injection. No cases of reaction, endophthalmitis, retinal breaks, retinal detachment, or vitreous

Table 4 Correlation between BCVA by logMAR and both the spherical equivalent and CMT after 6 months

\begin{tabular}{lll}
\hline & \multicolumn{2}{l}{ BCVA by log MAR after 6 months } \\
\cline { 2 - 3 } & r. & $P$ \\
\hline Total eyes & \\
Spherical equivalent & -0.346 & 0.135 \\
CMT after 6 months & 0.338 & 0.145 \\
$<\mathbf{4 0}$ years & \\
Spherical equivalent & -0.051 & 0.905 \\
CMT after 6 months & 0.027 & 0.950 \\
$\geq$ 40 years & & \\
Spherical equivalent & -0.335 & 0.440 \\
CMT after 6 months & 0.286 & 0.152 \\
\hline
\end{tabular}

$r$ Pearson correlation co-efficient, CMT Central macular thickness, BCVA Best corrected visual acuity 


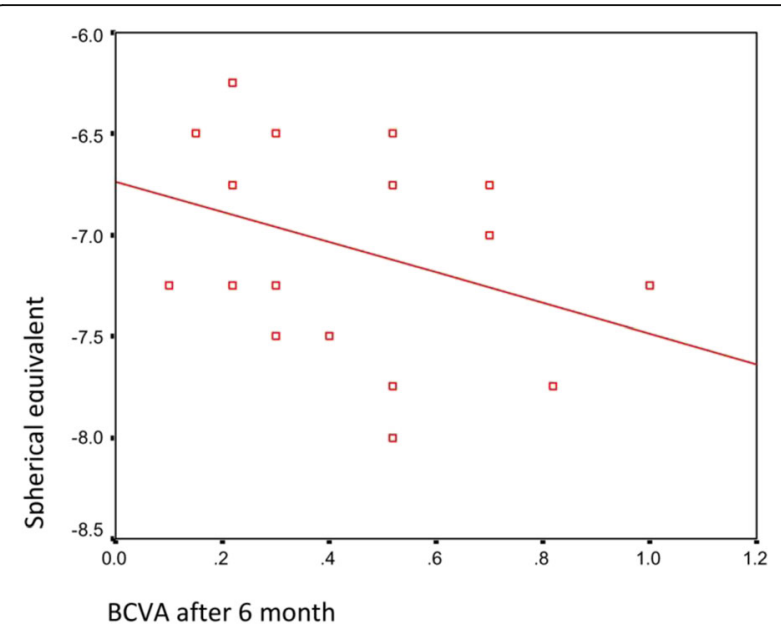

Fig. 1 Correlation between the BCVA after 6 months and spherical equivalent in all eyes

haemorrhage were reported. No systemic complications, such as myocardial infarction, stroke or death, were reported during the study. For example, in a 55-year-old female patient with active myopic $\mathrm{CNV}$ and retinal haemorrhages as documented by fluorescein angiography (Fig. 3), BCVA improved after 3 consecutive injections, from 1 to 0.52 (by LogMAR), and CMT declined, from $260 \mu \mathrm{m}$ (Fig. 4) to $226 \mu \mathrm{m}, 213 \mu \mathrm{m}$, and $184 \mu \mathrm{m}$ after 3 monthly injections (Fig. 5a, b, c). CNV remained inactive until the last follow-up visit.

\section{Discussion}

Various methods, such as laser photocoagulation, transpupillary thermotherapy (TTT), PDT (photodynamic therapy), submacular surgery, and macular translocation, were attempted to treat myopic $\mathrm{CNV}$ before the era of

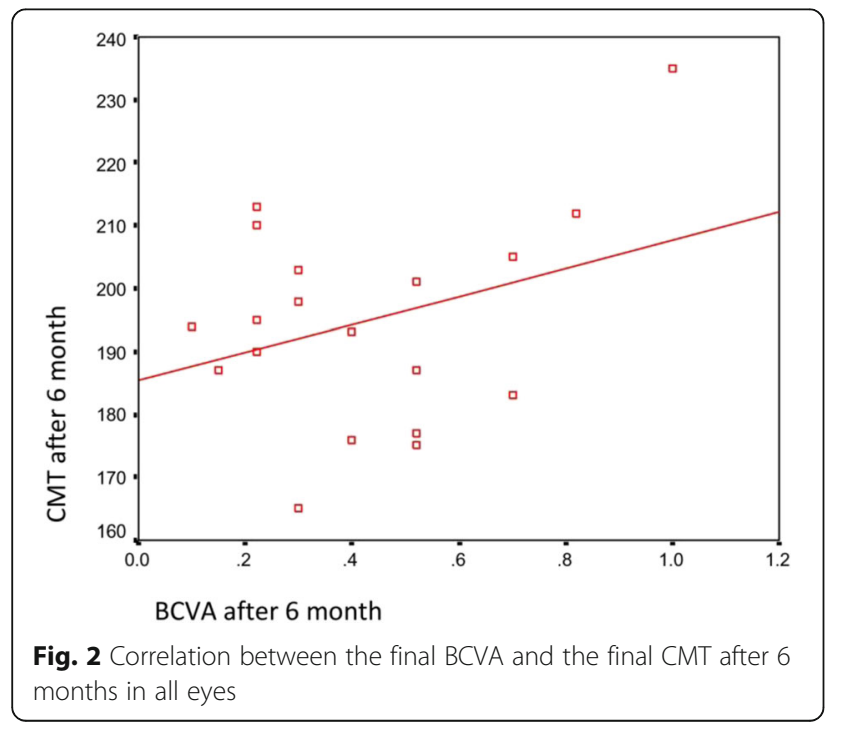

anti-VEGF. Despite all these attempted treatment approaches, the results were unsatisfactory, with no evident clinical improvement. Damage to adjacent photoreceptors and atrophic scar progression hindered clinical improvements and decreased BCVA in laser photocoagulation-treated patients with subfoveal CNV due to age-related macular degeneration [12, 13], with even poorer results in patients with myopic extrafoveal CNV despite the cease of activity [14-17].

This advocated the shift to PDT with verteporfin, which resulted in more satisfactory results angiographically and clinically in myopic CNV patients. Many studies have supported the use of verteporfin, especially those reported by the Photodynamic Therapy Study Group, which detected an improvement in BCVA in the PDTtreated group in the first 2 years that declined afterward $[4,18]$. Another study that included 24 eyes of myopic $\mathrm{CNV}$ patients reported that PDT may result in good visual outcomes in patients with extrafoveal CNV lesions when the laser spot is adjusted to spare the fovea [19].

Regarding anti-VEGF treatment for myopic CNV, Baba et al. [20] compared the efficacy of bevacizumab and PDT. Intravitreal bevacizumab showed a greater improvement in BCVA than PDT in eyes with myopic CNV. Additionally, Arias et al. [21] found that the mean visual acuity improved by 8.4 letters following an average of 1.5 intravitreal bevacizumab injections after 6 months of follow-up. Another study conducted by Ikuno et al. [22] reported an improvement in the mean BCVA in a case series of 63 eyes of myopic $\mathrm{CNV}$ following one to six bevacizumab injections.

during 12 months of observation. Regarding ranibizumab, the REPAIR study [23, 24] reported an improvement of 13.8 letters following a median of 3 ranibizumab injections based on the PRN regimen after 12 months. The RADIANCE study confirmed the results of the REPAIR study [8], which showed that approximately $40 \%$ of ranibizumab-treated patients gained 15 or more letters of visual acuity at the third month compared with only $15 \%$ of PDT-treated patients. After 1 year, BCVA improved by 13.8 letters in the first group treated with ranibizumab (based on visual acuity stabilisation in the preceding two follow-up visits) and 14.4 letters in the second group treated with ranibizumab (based on disease activity criteria) compared with 9.3 letters in the group treated with PDT. In addition, some patients in the PDT group switched to ranibizumab from the third month onwards (with a median number of 2.0 injections between months 3 and 12).

Another case series conducted on ranibizumab in 16 patients with myopic CNV by Lai et al. [25] reported an improvement in the mean BCVA of 3 lines after 1 year in $75 \%$ of eyes, with recurrence demonstrated by angiography in only two eyes after 3 months that required 

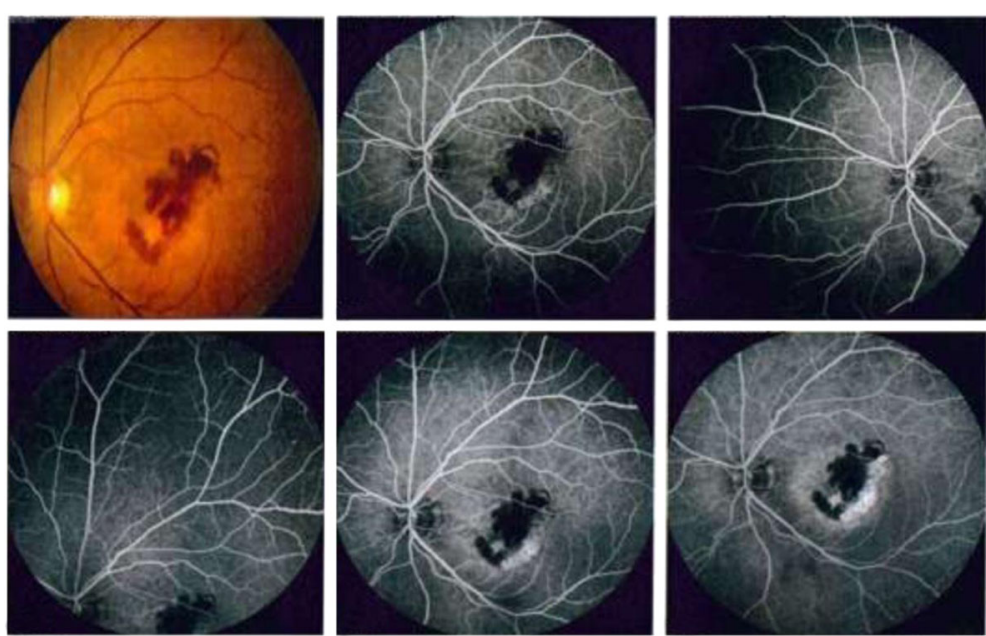

Fig. 3 Fluorescein angiography of a female patient 55 years old with left active myopic subfoveal CNV

retreatment between the 3rd and 9th months. A significant reduction in the mean central foveal thickness by OCT was also reported.

Another study by Chen et al. [26] compared the efficacy of ranibizumab and PDT in myopic CNV patients and revealed that in Asian patients, ranibizumab achieved superior efficacy compared to verteporfin photodynamic therapy at the third month, with continuation of its

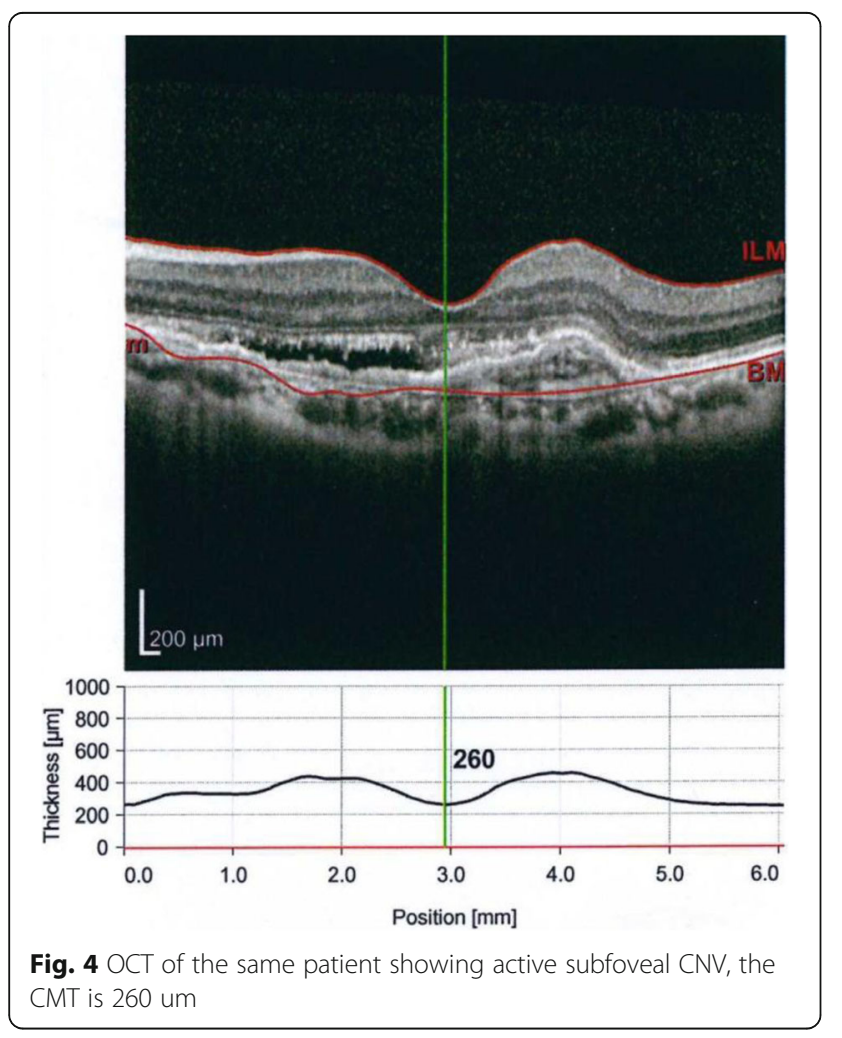

therapeutic effect at month 12. Furthermore, a recent 5year, prospective, multicenter study that was conducted on ranibizumab in myopic $\mathrm{CNV}$ in 488 clinical sites in 42 countries revealed tremendous VA gains in treatmentnaive patients and VA maintenance in patients previously treated with ranibizumab [27].

With respect to aflibercept in myopic CNV, the MYRROR study reported a mean change of +13.5 letters in BCVA in aflibercept-treated patients after a median of two injections within 12 weeks that was maintained throughout 48 weeks compared with +3.9 letters in sham-treated patients. No further injections were needed throughout the study. Visual gain correlated significantly with a reduction in central retinal thickness [9]. Other studies confirmed the efficacy of aflibercept in myopic $\mathrm{CNV}$ patients. For example, Brue and co-authors showed an improvement in BCVA from 0.69 LogMAR to 0.15 LogMAR after 18 months [28]. Moreover, Pece and Milani reported an improvement of 10.6 letters after 1 year of follow-up [29].

The present study evaluated the efficacy and safety of ziv-aflibercept in myopic $\mathrm{CNV}$ patients and reported that fewer injections were needed in patients younger than 40 years. In addition, $\mathrm{CNV}$ was smaller in the younger age group, with a more notable improvement in BCVA. These results are similar to those of Yoshida et al. [30], who also showed more notable clinical improvements with a smaller $\mathrm{CNV}$ in patients younger than 40 years. To explain the less notable improvement in older patients, several factors, such as decreased integrity and function of the retinal pigment epithelium in myopic patients, may be involved, as these might reduce the inhibition of angiogenesis, leading to the formation of a larger and more active $\mathrm{CNV}$, as well as a delay in the regression of $\mathrm{CNV}$ in older patients. Moreover, 

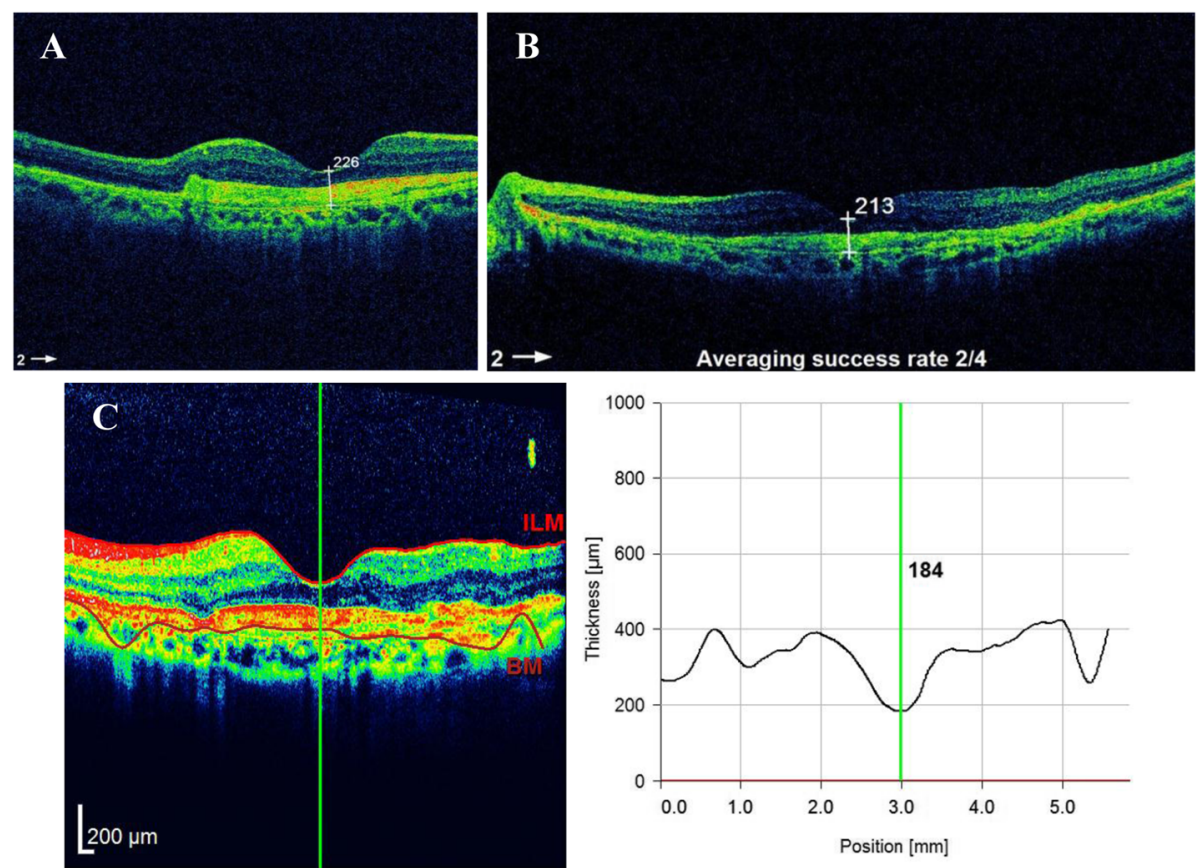

Fig. $\mathbf{5}$ a OCT after the first injection of ziv-aflibercept with reduced CMT to $226 \mathrm{um}$. b OCT after the second injection of ziv-aflibercept with reduced CMT to $213 \mathrm{um}$. c OCT after the third injection of ziv-aflibercept, the CMT declined to 184 um

myopic CNV in older patients shows a clinicopathological correlation with both AMD and high myopia and tends to correlate with chorioretinal atrophic changes that markedly affect visual acuity [20]. Another study evaluated the influence of ethnicity and age on the response to ranibizumab injection in myopic $\mathrm{CNV}$ and revealed that East Asians showed better BCVA gains than Caucasians. Variable numbers of injections were given to the different subgroups, indicating the need for individualized treatment [31].

Additionally, the improvement in BCVA and the reduction in CMT after injection were achieved in both groups, with statistical significance that reflects the efficacy of the new drug in myopic CNV patients with a high safety profile and low cost. This finding was quite similar to those from recent studies performed on zivaflibercept on a larger number of patients [32, 33] that discussed the application of ziv-aflibercept in different retinal diseases and detected a reasonable safety profile for the drug comparable with those of other anti-VEGF agents. Moreover, Braimah et al. [11] studied the efficacy of ziv-aflibercept on retinal diseases other than AMD, such as high myopia, macular telangiectasia, central serous chorioretinopathy, choroidal osteoma, choroiditis, Best's disease and idiopathic macular degeneration, and reported a marked reduction in CMT and a moderate improvement in BCVA.

In contrast, a study performed by Chhablani et al. on patients with age-related macular degeneration suggested immediate IOP elevation after injection in four eyes that needed anterior chamber paracentesis [34]. Anterior chamber paracentesis was not performed in the present study, as IOP did not change significantly after the injection of ziv-aflibercept either immediately or an extended period of time. This demonstrates the safety of ziv-aflibercept on IOP.

The costs per dose of intravitreal bevacizumab and ziv-aflibercept are low [35, 36]; however, those of aflibercept and ranibizumab are 20 to 30 times higher [37]. Thus, this drug can be of great benefit in low-income countries with deficient insurance coverage.

The main limitations of this study are the small number of patients, the short duration of follow-up (6 months) and the lack of a control group; thus, a larger number of patients and a longer follow-up period are needed to confirm our results.

\section{Conclusion}

Ziv aflibercept is a cheap and effective anti-VEGF agent in patients with active myopic CNV, with a high safety profile. The authors recommend the use of this new anti-VEGF agent in retinal diseases such as myopic $\mathrm{CNV}$. However, a larger number of patients and a longer follow-up period are needed in further studies to confirm these results.

\section{Abbreviations}

AMD: Age-related macular degeneration; BCVA: Best corrected visual acuity; CMT: Central macular thickness; CNV: Choroidal neovascularisation; 
FFA: Fundus fluorescein angiography; IOP: Intraocular pressure; OCT: Optical coherence tomography; PDT: Photodynamic therapy; TT: Transpupillary thermotherapy; VEGF: Vascular endothelial growth factor

\section{Acknowledgments}

The authors would like to acknowledge Tanta University Eye Hospital, Tanta University in which the whole study was performed, in addition, authors are grateful to Springer Nature author Services who edited the manuscript for proper English language, grammar, puctuation, spelling, and overall style by one or more of their highly qualified native English speakers editors.

\section{Authors' contributions}

AEN performed clinical examination, investigations like fundus fluorescein angiography and optical coherence tomography and intravitreal injection of all patients during the period of the research. HMS performed examination and follow up of all patients, data collection, statistical analysis and results of the research. All authors shared in writing, reading, and approval of the manuscript.

\section{Funding}

The research was not supported by any funding agent.

\section{Availability of data and materials}

The datasets used during the current study are available from the corresponding author on a reasonable request.

\section{Ethics approval and consent to participate}

The research was approved by the Ethical Committee of the Faculty of Medicine, Tanta University, Egypt (approval code 32970/02/19). Written consent was obtained from all participants.

\section{Consent for publication}

Not available.

\section{Competing interests}

The authors declare that they have no competing interests.

Received: 30 March 2020 Accepted: 5 October 2020

Published online: 19 October 2020

\section{References}

1. Wong TY, Foster PJ, Hee J, et al. Prevalence and risk factors for refractive errors in adult Chinese in Singapore. Invest Ophthalmol Vis Sci. 2000:41: 2486-94.

2. Wong TY, Ferreira A, Hughes R, et al. Epidemiology and disease burden of pathologic myopia and myopic choroidal neovascularization: an evidencebased systematic review. Am J Ophthalmol. 2014;157:9-25.e12.

3. Lam DSC, Chan W-M, Liu DT, et al. Photodynamic therapy with verteporfin for subfoveal choroidal neovascularization of pathological myopia in Chinese eyes: a prospective series of 1 and 2 year follow up. $\mathrm{Br} J$ Ophthalmol. 2004;88:1315-9.

4. Verteporfin in Photodynamic Therapy Study Group. Photodynamic therapy of subfoveal choroidal neovascularization in pathologic myopia with verteporfin. 1-year results of a randomized clinical trial-VIP report no. 1. Ophthalmology. 2001;108:841-52.

5. Chan WM, Ohji M, Lai TY, et al. Choroidal neovascularization in pathological myopia: an update in management. Br J Ophthalmol. 2005;89:1522-8.

6. Papadopoulos N, Martin J, Ruan Q, et al. Binding and neutralization of vascular endothelial growth factor (VEGF) and related ligands by VEGF Trap, ranibizumab and bevacizumab. Angiogenesis. 2012;15(2):171-85.

7. Deissler HL, Lang GK, Lang GE. Capacity of aflibercept to counteract VEGFstimulated abnormal behaviour of retinal microvascular endothelial cells. Exp Eye Res. 2014;122:20-31.

8. Wolf S, Balciuniene VJ, Laganovska G, et al. RADIANCE: a randomized controlled study of ranibizumab in patients with choroidal neovascularization secondary to pathologic myopia. Ophthalmology. 2014 121(3):682-92

9. Ikuno $Y$, Ohno-Matsui $K$, Wong $T Y$, et al. Intravitreal aflibercept injection in patients with myopic choroidal neovascularization: the MYRROR study. Ophthalmology. 2015;122(6):1220-7.
10. Chhablani J, Narayanan R, Mathai A, et al. Short-term safety profile of intravitreal ziv-aflibercept. Retina. 2016;36(6):1126-31.

11. Braimah IZ, Stewart M, Videkar C, Dedhia CJ, Chhablani J. Intravitreal zivaflibercept for the treatment of choroidal neovascularisation associated with conditions other than age-related macular degeneration. Br J Ophthalmol. 2017:101(9):1201-5.

12. Macular Photocoagulation Study Group. Laser photocoagulation of subfoveal neovascular lesions of age-related macular degeneration. Updated findings from two clinical trials. Arch Ophthalmol. 1993;111(9): 1200-9.

13. Macular Photocoagulation Study Group. Visual outcome after laser photocoagulation for subfoveal choroidal neovascularization secondary to age-related macular degeneration. The influence of initial lesion size and initial visual acuity. Arch Ophthalmol. 1994;112(4):480-8.

14. Secretan M, Kuhn D, Soubrane G, et al. Long-term visual outcome of choroidal neovascularization in pathologic myopia: natural history and laser treatment. Eur J Ophthalmol. 1997:7(4):307-16.

15. Tano Y. Pathologic myopia: where are we now? Am J Ophthalmol. 2002; 134:645-60.

16. Virgili G, Menchini F. Laser photocoagulation for choroidal neovascularisation in pathologic myopia. Cochrane Database Syst Rev. 2005; 19(4):CD004765.

17. Ruiz-Moreno JM, Montero JA. Long-term visual acuity after argon green laser photocoagulation of juxtafoveal choroidal neovascularization in highly myopic eyes. Eur J Ophthalmol. 2002;12:117-22.

18. Blinder KJ, Blumenkranz MS, Bressler NM, et al. Verteporfin therapy of subfoveal choroidal neovascularization in pathologic myopia: 2-year results of a randomized clinical trial - VIP report no. 3. Ophthalmology. 2003;110(4): $667-73$.

19. Tan CS, Chew MC, Lim TH. Comparison of foveal-sparing with fovealinvolving photodynamic therapy for myopic choroidal neovascularization. Eye (Lond). 2014;28:17-22.

20. Baba T, Kubota-Taniai M, et al. Two-year comparison of photodynamic therapy and intravitreal bevacizumab for treatment of myopic choroidal neovascularisation. Br J Ophthalmol. 2010;94(7):864-70.

21. Arias L, Planas N, Prades $S$, et al. Intravitreal bevacizumab (Avastin) for choroidal neovascularisation secondary to pathological myopia: 6-month results. Br J Ophthalmol. 2008:92(8):1035-9.

22. Ikuno Y, Sayanagi K, Soga K, et al. Intravitreal bevacizumab for choroidal neovascularization attributable to pathological myopia: one-year results. Am J Ophthalmol. 2009;147(1):94-100.

23. Tufail A, Patel PJ, Sivaprasad S, et al. Ranibizumab for the treatment of choroidal neovascularisation secondary to pathological myopia: interim analysis of the REPAIR study. Eye (Lond). 2013;27(6):709-15.

24. Tufail A, Narendran N, Patel PJ, et al. Ranibizumab in myopic choroidal neovascularization: the 12-month results from the REPAIR study. Ophthalmology. 2013;120(9):1944-5.

25. Lai TY, Chan WM, Liu DT, et al. Intravitreal ranibizumab for the primary treatment of choroidal neovascularization secondary to pathologic myopia. Retina. 2009;29(6):750-6.

26. Chen Y, Sharma T, Li X, Song Y, Chang Q, Lin R, Lai TY. Ranibizumab versus verteporfin photodynamic therapy in Asian patients with myopic choroidal neovascularization: BRILLIANCE, a 12-month, randomized, double-masked study. Retina (Philadelphia, Pa.). 2019;39(10):1985.

27. Hamilton RD, Clemens A, Minnella AM, Lai TY, Dai H, Sakamoto T, LUMINOUS study group. Real-world effectiveness and safety of ranibizumab for the treatment of myopic choroidal neovascularization: Results from the LUMINOUS study. PLoS One. 2020;15(1):e0227557.

28. Bruè C, Pazzaglia A, Mariotti C, Reibaldi M, Giovannini A. Aflibercept as primary treatment for myopic choroidal neovascularisation: a retrospective study. Eye (Lond). 2016;30:139-45. https://doi.org/10.1038/eye.2015.199.

29. Pece A, Milani P. Intravitreal aflibercept for myopic choroidal neovascularization. Graefes Arch ClinExp Ophthalmol. 2016;254:2327-32. https://doi.org/10.1007/s00417-016-3396-9.

30. Yoshida T, Kyoko Ohno-Matsui K, et al. Long-term visual prognosis of choroidal neovascularization in high myopia. A comparison between age groups. Ophthalmology. 2002;109:712-9.

31. Holz FG, Tufail A, Leveziel N, Lai TY, Lanzetta P, Wong TY, et al. Ranibizumab in myopic choroidal neovascularization: a subgroup analysis by ethnicity, age, and ocular characteristics in RADIANCE. Ophthalmologica. 2016;236(1): 19-28. 
32. Mansour AM, Ashraf M, Charbaji A, et al. Two-year outcomes of intravitreal ziv-aflibercept. B J Ophthalmol. 2018;102(10):1387-90.

33. Ziv-aflibercept Study Group. Safety of 5914 intravitreal ziv-aflibercept injections. Br J Ophthalmol. 2019:103(6):805-10.

34. Chhablani J, Dedhia CJ, Peguda HK, Stewart M. Short-term safety of $2 \mathrm{mg}$ intravitreal ziv-aflibercept. Retina (Philadelphia, Pa). 2017;37(10):1859-65.

35. Mansour AM, Al-Ghadban SI, Yunis MH, El-Sabban ME. Ziv-aflibercept in macular disease. Br J Ophthalmol. 2015;99:1055-9 [PMCID: PMC4518747] [PubMed: 25677668].

36. Singh SR, Dogra A, Stewart M, Das T, Chhablani J. Intravitreal ziv-aflibercept: clinical effects and economic impact. Asia Pac J Ophthalmol (Phila). 2017;6: 561-8 [PubMed: 28971631].

37. Ross EL, Hutton DW, Stein JD, Bressler NM, Jampol LM, Glassman AR. Costeffectiveness of aflibercept, bevacizumab, and ranibizumab for diabetic macular edema treatment: Analysis from the diabetic retinopathy clinical research network comparative effectiveness trial. JAMA Ophthalmol. 2016; 134:888-96 [PMCID: PMC6648661] [PubMed: 27280850].

\section{Publisher's Note}

Springer Nature remains neutral with regard to jurisdictional claims in published maps and institutional affiliations.

Ready to submit your research? Choose BMC and benefit from:

- fast, convenient online submission

- thorough peer review by experienced researchers in your field

- rapid publication on acceptance

- support for research data, including large and complex data types

- gold Open Access which fosters wider collaboration and increased citations

- maximum visibility for your research: over $100 \mathrm{M}$ website views per year

At BMC, research is always in progress.

Learn more biomedcentral.com/submissions 